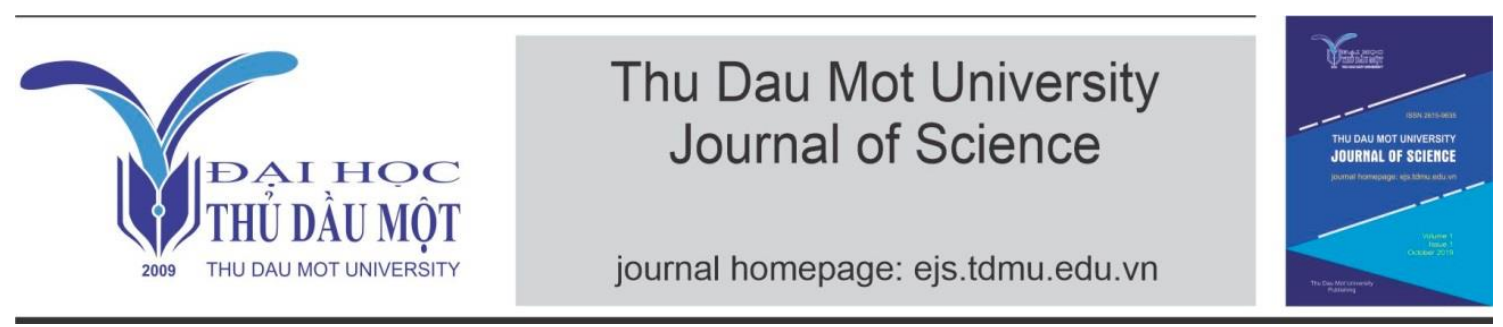

\title{
Environmental Risk Assessment of Organic Pollution on Wastewater on Industrial Parks in Bien Hoa City
}

By Tran Cong Hau, Nguyen Hien Than (Thu Dau Mot University)

Article Info: Received 20 Aug 2020, Accepted 25 Nov 2020, Available online 15 Dec, 2020

Corresponding author: thannh@tdmu.edu.vn

https://doi.org/10.37550/tdmu.EJS/2020.04.086

\begin{abstract}
Bien Hoa City is an urban area of Dong Nai province located in the Southern key economic region. Currently, Bien Hoa City has 6 industrial parks in operation with large daily wastewater flow, causing environmental risks, especially from organic pollutants. The study applied the Nemerow risk index and the geographic information systems (GIS). The results showed that the industrial parks were mainly organic pollution levels including N-total, P-total, and Ammonium. The level of environmental risk from organic pollution was recorded in range of medium to very high levels, the ranked in descending order: Agtex Long Binh Industrial Park $(P=24)>$ Amata Industrial Park $(P=16)>$ Bien Hoa 2 Industrial Park $(P=10)$, > Tam Phuoc Industrial Park $(P=5)>$ Loteco Industrial Park $(P=3)$. The results of the study provided good information for the management and improvement of wastewater quality in the industrial wastewater treatment plants of the industrial parks in Bien Hoa City.
\end{abstract}

Keywords: organic pollution, environmental risk, Nemerow index

\section{Introduction}

The environment is the collection of all the natural and artificial elements surrounding people, affecting human life such as air, water, humidity, organisms, commune human 
associations and institutions. Therefore, just one factor changed, will affect the environment causing environmental risk. Environmental risk is the likelihood of hazard or the likelihood of injury, illness, or death due to exposure to a potential environmental hazard (Covello \& Merkhoher, 1993). Among the causes of pollution impacting the environment, industrial wastewater is one of the main reasons. As a result, the study of the assessment of industrial wastewater risk to the environment is essential. Over the years, many researchers have carried out industrial wastewater risk assessment for the environment and ecosystems. (Shinta, Karnaningroem, \& Mardyanto, 2019), conducted wastewater risk assessment of a treatment plant using the failure mode and effects analysis (FMEA) and fishbone diagrams. The results of this study indicated the potential risk of wastewater treatment but level of environmental risk was not assessed. (Wang \& Yang, 2016), assessed industrial wastewater pollution to health using correlated regression models. The results of this study didn't show the risk level of pollution parameters. One of the methods of environmental risk assessment used widely in many previous studies is the Nemerow index published by N.L. Nemerow published in 1974 (Nemerow, 1974). A variety of researched applied the Nemerow index such as (Sulthonuddin, Hartono, Utomo, \& Said, 2019), the Nemerow index method was used to assess the water quality of the Cimanuk River in West Java, (Yi, Sun, Tang, \& Zhang, 2016), assessed the ecological risk of heavy metals in upstream sediments of the Yangtze River. Similar to Jie and partner (Jie, Qing, \& Hui, 2012), used the improved Nemerow index method based on Entropy weight to assess groundwater quality, and (Jing, 2006), studied the numerical application of the Nemerow index in environmental seawater assessment in the vicinity of terrestrial sewers. Besides, some studies on environmental risk assessment were also carried out in Vietnam such as (Ngô, 2014), assessed the ecological risks for industrial wastewater in Dung Quat economic zone and industrial parks.Quang Ngai and (Phạm, 2013), assessed ecological risks for wastewater from Lien Chieu Industrial Parkin Da Nang city.

Dong Nai is currently a locality with the top economic growth rate in Vietnam. Bien Hoa City is the capital city of Dong Nai province, located in the West of Dong Nai province, and part of the Ho Chi Minh City metropolitan area and located about 30 kilometers (20 mi) east of Ho Chi Minh City. Bien Hoa city is now an industrial center of southern Vietnam and many factories and warehouses. Currently, there are 6 industrial parks in operation in the area surrounding the city. Industrial parks operate in a range of industrial fields . Currently, most of the industrial parks in the Bien Hoa City have already wastewater treatment systems. However, the treatment efficiency of some organic pollutants exceeded the National Technical Regulation on industrial wastewater. Therefore, the analysis and assessment of the current status of wastewater treatment of industrial parks to the environmental risk caused by organic pollution plays an 
important role in the city. The results of the study will provide necessary information on the wastewater treatment situation in industrial parks and the level of environmental risks affected by organic pollution from industrial wastewater to help the government and researchers make decisions on planning and proposing measures.

\section{Materials and methods}

\section{Materials}

The data was collected from reports of wastewater monitoring tasks in wastewater treatment systems of industrial parks in Dong Nai province in 2019 at 5 industrial parks in the city. Bien Hoa City includes Bien Hoa 2 Industrial Park Amata Industrial Park, Loteco Industrial Park, Agtex Long Bình Industrial Park, Tam Phước Industrial Park was observed. Some parameters monitored in this study including $\mathrm{pH}, \quad \mathrm{N}$-total, P-total, Ammonium, $\mathrm{BOD}_{5}, \mathrm{COD}$, Fluoride. Monitoring frequency is 12 times/year.

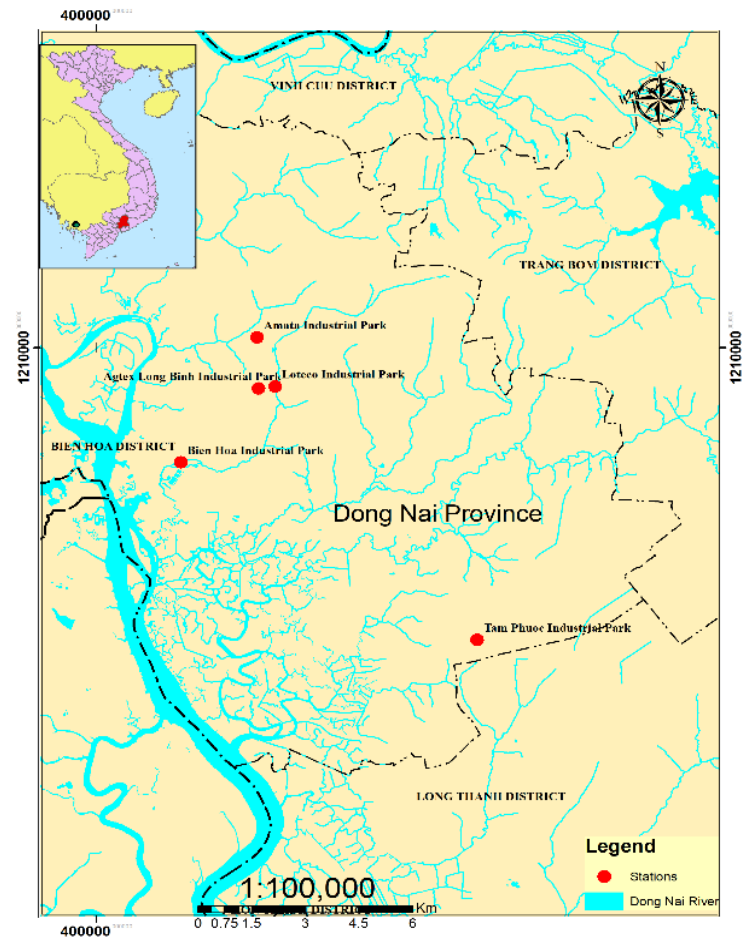

Figure 1. The map of monitoring stations

\section{Methods}

\section{The Nemerow risk index}

In this study, the author used the Nemerow pollution index to assess the environmental risks from organic pollution of industrial wastewater. The Nemerow pollution index is given by N.L. Nemerow announced in 1974 (Nemerow, 1974). This index has used in many studies to evaluate water quality such as(Yulin \& Zhenchang, 1989), (Islam, Ahmed, Raknuzzaman, Habibullah-Al-Mamun, \& Islam, 2015)... The assessment process was outlined as follows.

Step 1: Collecting monitoring data. In this study, the data of the monitoring wastewater in 2019 were used.

Step 2: Calculating the number of exceeding the standard and determining the level of wastewater pollution based on the following formula: 
$P_{s}=\sqrt{\frac{P_{a v e}^{2}+P_{\max }^{2}}{2}}$

Of which:

- Ps is the target of the Nemerow pollution index

- Pave is the average value of the pollution index (Pi) of all pollutants

- Pmax is the highest value of the pollution index (Inengite, Abasi, \& Walter, 2015; Jie et al., 2012).

According to equation 1, the weights of the pollution parameters are the same. However, the degree of influence of the parameters on the wastewater quality is different according to many opinions of the authors. In this study, the Entropy weighting method was conducted to determine the contribution level of the parameters. The formula for calculating the Nemerow pollution index is improved as follows (Zhang, Feng, \& Hao, 2018):

$$
P_{s}=\sqrt{\frac{\left(\mathrm{W}_{i} P_{i}\right)^{2}+P_{\max }^{2}}{2}}
$$

In which, $\mathrm{Wi}$ is the weight of the $\mathrm{i}$ single pollutants.

The results of the Nemerow pollution index were compared with the rating scale to determine the level of pollution. The results are classified into 5 levels: Very good $\mathrm{P}<1$, Good $1<\mathrm{P}<2$, Medium risk $2<\mathrm{P}<3$, High risk $3<\mathrm{P}<5$, extreme high risk $\mathrm{P}>5$ (Tao, Yujia, \& HUANG, 2011; Zhang et al., 2018).

\section{Entropy weighting method:}

In order to increase the objectivity and accuracy of the results in the environmental risk assessment, the Entropy weight was applied.

Entropy is a physical concept in thermodynamic systems used to describe the degree of system disturbance, the greater the Entropy value, the greater the degree of disturbance. Later the idea of Entropy was developed in information theories and has been widely applied in the fields of economic management and other systems analysis disciplines. Entropy is used to measure the size of the amount of information, the more information contained in a particular indicator, the more important that the indicator's influence in decision-making becomes. Therefore, Entropy is also applied to assign weights to the environmental parameters (Zhang et al., 2018). The exact steps for determining Entropy weights are as follows: 
Step 1: Standardization of the original data matrix: assuming there are $\mathrm{m}$ monitoring stations and $\mathrm{n}$ evaluation parameters, the original data matrix $\mathrm{X}$ is as follows:

$\mathrm{X}=\left[\begin{array}{cccc}\mathrm{x}_{11} & \mathrm{x}_{12} & \ldots & \mathrm{x}_{1 \mathrm{n}} \\ \mathrm{x}_{21} & \mathrm{x}_{22} & \cdots & \mathrm{x}_{2 \mathrm{n}} \\ \vdots & \vdots & \vdots & \vdots \\ \mathrm{x}_{\mathrm{m} 1} & \mathrm{x}_{\mathrm{m} 2} & \ldots & \mathrm{x}_{\mathrm{mn}}\end{array}\right]\left[\begin{array}{cccc}\mathrm{X}_{11} & \mathrm{x}_{12} & \ldots & \mathrm{x}_{1 \mathrm{n}} \\ \mathrm{x}_{21} & \mathrm{x}_{22} & \ldots & \mathrm{x}_{2 \mathrm{n}} \\ \vdots & \vdots & \vdots & \vdots \\ \mathrm{x}_{\mathrm{m} 1} & \mathrm{x}_{\mathrm{m} 2} & \ldots & \mathrm{x}_{\mathrm{mn}}\end{array}\right]$, After normalization there are matrices $R=($ rij $) m \times n(i=1,2, \ldots, m ; j=1,2, \ldots, n)$

where, rij is the normalized value of the observation samples $\mathrm{j}$ in the parameter $\mathrm{i}$; rij $\in$ $[0,1]$

- Parameters with larger values are standardized against the formula:

$$
\operatorname{rij}=[x i j-\min (x j)] /[\max (x j)-\min (x j)]
$$

- Parameters with smaller values are standardized according to the formula:

$$
\text { rij }=1-[x i j-\min (x j)] /[\max (x j)-\min (x j)]
$$

In which, two $\mathrm{pH}$ parameters are amphoteric parameters, calculated in combination between two formulas:

If $\mathrm{pH}<6$, use formula (1), otherwise use formula (2).

If DO\% bh <88, use formula (1), otherwise use formula (2)

Step 2: Define Entropy:

$$
\mathrm{Hi}=-\frac{1}{\operatorname{lnn}} \sum_{j=1}^{\mathrm{n}} \mathrm{f}_{\mathrm{ij}} \frac{1}{\ln n} \sum_{j=1}^{\mathrm{n}} \mathrm{f}_{i j} \ln (\mathrm{fij})
$$

$$
\text { where, fij = rij/ } \sum_{\mathrm{j}=1}^{\mathrm{n}}
$$

$\sum_{j=1}^{n} r_{i j}, 0 \leq \mathrm{Hi} \leq 1$. However, when fij $=0$, then $\ln (\mathrm{fij})$ has no meaning. So, fij can be adjusted as follows: fij $=(1+$ rij $)$ / $\sum_{j=1}^{n} \underline{E}(1+$ rij $)$

$$
\sum_{j=1}^{n}\left(1+r_{i j}\right) \text { or when fij }=0 \text { then fij } \ln (f i j)=0 \text { (when fij }=0 \text { then } \ln \text { (fij) }
$$
has no meaning - the condition takes $\ln$ when fij $>0$ ). In this topic, when fij $=0$, the author chose fij $\ln (\mathrm{fij})=0$.

Step 3: Define entropy weight

Then, the entropy weight can be defined as 


$$
\text { wi = (1- Hi }) /\left(\mathrm{m}-\sum_{\mathrm{i}=1}^{\mathrm{m}} \sum_{\sum_{\mathrm{i}=1}^{\mathrm{m}} \mathrm{w}_{\mathrm{i}}=1 .}^{\mathrm{m}} \mathrm{H}_{\mathrm{i}}\right), 0 \leq \mathrm{wi} \leq 1, \sum_{\mathrm{i}=1}^{\mathrm{m}} \mathrm{w}_{\mathrm{i}}
$$

The result of Entropy calculation is to find the weights of parameters $\mathrm{pH}$, Total Nitrogen, Total P, Ammonium, BOD 5 , COD, Fluoride to calculate the risk of pollution from wastewater as follows: [pH, N-total,P-total, Ammonium, $\mathrm{BOD}_{5}, \mathrm{COD}$, Fluoride $]=$ $[0.035,0.078,0.187,0.479,0.082,0.056,0.082]$.

\section{Results and discussion}

\subsection{Current situation of industrial wastewater collection in Bien Hoa city, Dong Nai province}

In Bien Hoa City, Dong Nai province, there are 6 industrial parks in operation, including industrial parks: Bien Hoa 1, Bien Hoa 2, Loteco, Agtex Long Binh, Amata, Tam Phuoc..

\begin{tabular}{|c|c|c|c|c|c|c|}
\hline No. & Name & Acreage & $\begin{array}{c}\text { Filling } \\
\text { rate }\end{array}$ & Discharge flow & \multicolumn{2}{|c|}{$\begin{array}{c}\text { Main treatment } \\
\text { technology }\end{array}$} \\
\hline 1 & $\begin{array}{l}\text { Agtex Long } \\
\text { Binh Industrial } \\
\text { Park }\end{array}$ & 43 ha & $90 \%$ & $\begin{array}{l}5 \quad \text { manufactures } \\
\text { connected to the system }\end{array}$ & $\begin{array}{l}\text { Aerotank } \\
\text { sludge }\end{array}$ & activated \\
\hline 2 & $\begin{array}{l}\text { Amata } \\
\text { Industrial Park }\end{array}$ & 513 ha & $90.67 \%$ & $5,600-6900 \mathrm{~m}^{3} /$ day & $\begin{array}{l}\text { Aerotank } \\
\text { sludge }\end{array}$ & activated \\
\hline 3 & $\begin{array}{l}\text { Bien Hoa } \\
\text { Industrial Park }\end{array}$ & 365 ha & $100 \%$ & $\begin{array}{l}5,500-6,800 \mathrm{~m}^{3} / \text { day and } \\
\text { night }\left(1,500 \mathrm{~m}^{3} / \text { day }\right. \\
\text { connected from Bien } \\
\text { Hoa } 1 \text { Industrial Park })\end{array}$ & Unitank & \\
\hline 4 & $\begin{array}{l}\text { Loteco } \\
\text { Industrial Park }\end{array}$ & 100 ha & $100 \%$ & $7000 \mathrm{~m}^{3} /$ day & $\begin{array}{l}\text { Aerotank } \\
\text { sludge }\end{array}$ & activated \\
\hline 5 & $\begin{array}{l}\text { Tam Phuoc } \\
\text { Industrial Park }\end{array}$ & 323 ha & $100 \%$ & $2800-3200 \mathrm{~m}^{3} /$ day & C-tech & \\
\hline
\end{tabular}

TABLE 1. The information of wastewater treatment systems

As can be seen Table 1 showed that: the area of Agtex Long Binh Industrial Park is the smallest with 43 ha with the lowest occupancy rate of $90 \%$ among the industrial park. The largest area is Amata Industrial Park with 513 ha with $90.67 \%$ head mounting rate. 
The remaining industrial parks have an area of 100 - 365 ha with an occupancy rate of all $100 \%$. The largest wastewater flow is at Loteco Industrial Park with a wastewater flow of $7000 \mathrm{~m} 3$ / day. Agtex Long Binh Industrial Park There are only 5 industrial parks connected to the centralized wastewater treatment system. Tam Phuoc Industrial Park has a low wastewater flow of $2800-3200 \mathrm{~m}^{3} /$ day and night. The main treatment technology of the industrial parks in Bien Hoa city is Aerotank activated sludge. Also, there are other processing technologies such as Unitank and C-tech.

In general, the industrial parks in Bien Hoa city have a large area (from 43 to 513 ha) and a high occupancy rate (from 90-100\%). With a large amount of wastewater in each industrial park, there is a centralized wastewater treatment system to treat wastewater before being discharged into the environment. Thereby, we see that the current wastewater collection and treatment site in the industrial parks of Bien Hoa city is being done well.

3.2. Assessing the current status of wastewater treatment in industrial parks in Bien Hoa city, Dong Nai province

\section{Agtex Long Binh Industrial Park}

TABLE 2. Descriptive statistics of exceeding concentration in Agtex Long Binh Industrial Park

\begin{tabular}{|l|c|c|c|c|c|c|c|}
\hline \multicolumn{1}{|c|}{ Statistic } & $\mathbf{p H}$ & $\mathbf{N}$-total & P-total & Ammonium & BOD $_{\mathbf{5}}$ & COD & Fluoride \\
\hline Minimum & 1.0000 & 0.7100 & 0.4950 & 0.0280 & 0.1000 & 0.2000 & 0.0190 \\
\hline Maximum & 1.0000 & $\mathbf{1 . 7 9 5 0}$ & $\mathbf{1 . 1 9 0 0}$ & $\mathbf{1 . 1 3 6 0}$ & 0.4667 & 0.7467 & 0.2240 \\
\hline Mean & 1.0000 & 1.0896 & 0.8619 & 0.1888 & 0.2639 & 0.3956 & 0.1486 \\
\hline
\end{tabular}

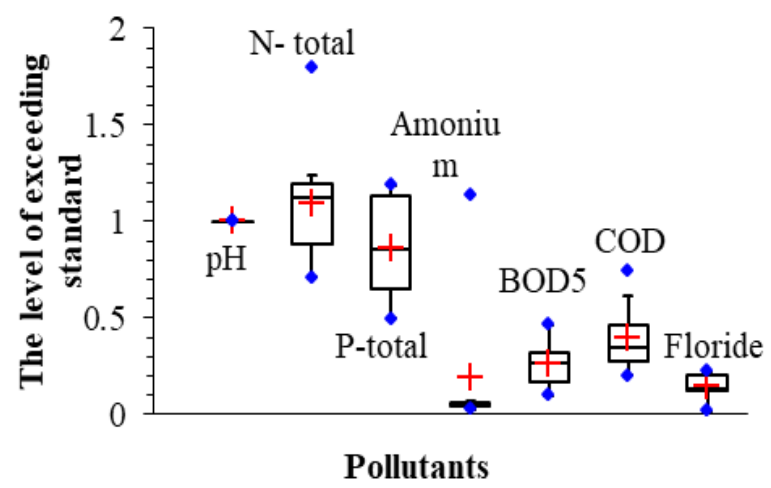

Figure 2: The exceeding level of observed parameters at Agtex Long Binh Industrial Park 
The Table 2 and the Figure 2 showed that the most of the parameters were within the permissible limits of QCVN 40:2011. N-total parameters exceeded at the maximum 1.795 times, on average exceeded 1.086 times. P-total and Ammonium parameters exceed the maximum standards of 1.19 and 1.13 times respectively. Thereby, it indicated that the current status of wastewater treatment in Agtex Long Binh Industrial Park does not treat parameters such as N-total, P-total, Ammonium. These are the organic parameters source from domestic wastewater. In fact, many enterprises in the industrial park mainly treated domestic wastewater through a 3-compartment septic tank and then connected to the industrial wastewater drainage system. The concentration of contamination N-total, P-total, Ammonium input exceeded the threshold of the treatment input of the centralized treatment plant which caused an unsatisfactory effluent output.

\section{Amata Industrial Park}

TABLE 3. Descriptive statistics exceeding concentration of Amata Industrial Park

\begin{tabular}{|l|l|l|l|l|l|l|l|}
\hline & $\mathrm{pH}$ & $\mathrm{N}$-total & P-total & Ammonium & \multicolumn{1}{|c|}{$\mathrm{BOD}_{5}$} & $\mathrm{COD}$ & Fluoride \\
\hline Minimum & 1.0000 & 0.4260 & 0.4150 & 0.0280 & 0.1000 & 0.2133 & 0.0660 \\
\hline Maximum & 1.0000 & 0.7400 & 0.7100 & 0.4220 & 0.3333 & 0.4400 & 0.1240 \\
Mean & 1.0000 & 0.5638 & 0.5665 & 0.0703 & 0.1778 & 0.2989 & 0.0930 \\
\hline
\end{tabular}

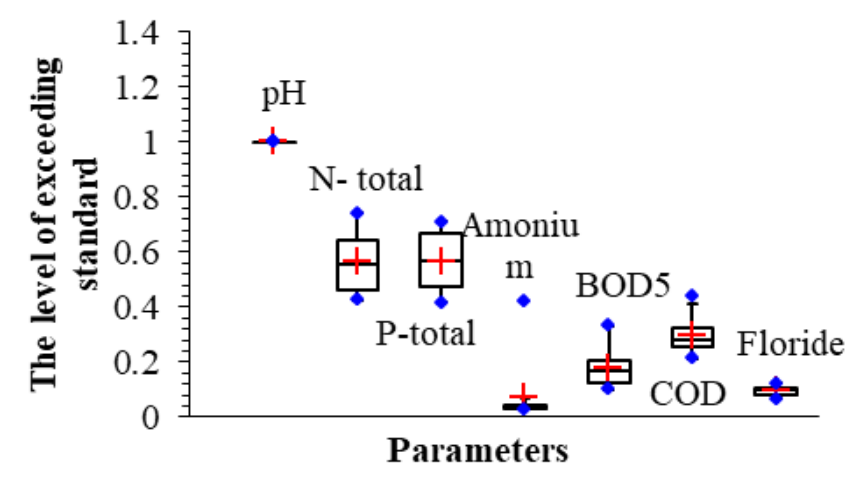

Figure 3. The exceeding level of polluted parameters Amata Industrial Park According to Table 3 and Figure 3, we found that pollution parameters in Amata Industrial Park were within the allowable limits of QCVN 40: 2011/BTNMT, and the excess values were less than $\leq 1$. It illustrated that the wastewater treatment system in Amata Industrial Park was good treatment efficiency. The incoming pollutants were well disposed of. 
Tran Cong Hau, Nguyen Hien Than- Volume 2 - Issue 4-2020, p.422-434.

\section{Bien Hoa 2 Industrial Park}

TABLE 4. Descriptive statistics of exceeding concentration in Bien Hoa 2 Industrial Park

\begin{tabular}{|l|l|l|l|l|l|l|l|}
\hline & $\mathbf{p H}$ & N-total & P-total & Ammonium & BOD $_{\mathbf{5}}$ & COD & Fluoride \\
\hline Minimum & 1.0000 & 0.4405 & 0.0475 & 0.0360 & 0.1000 & 0.1733 & 0.0960 \\
\hline Maximum & 1.0000 & 0.7900 & $\mathbf{1 . 9 7 5 0}$ & 0.1820 & 0.2000 & 0.3200 & 0.4340 \\
\hline Mean & 1.0000 & 0.6521 & 0.3623 & 0.0725 & 0.1556 & 0.2400 & 0.2370 \\
\hline
\end{tabular}

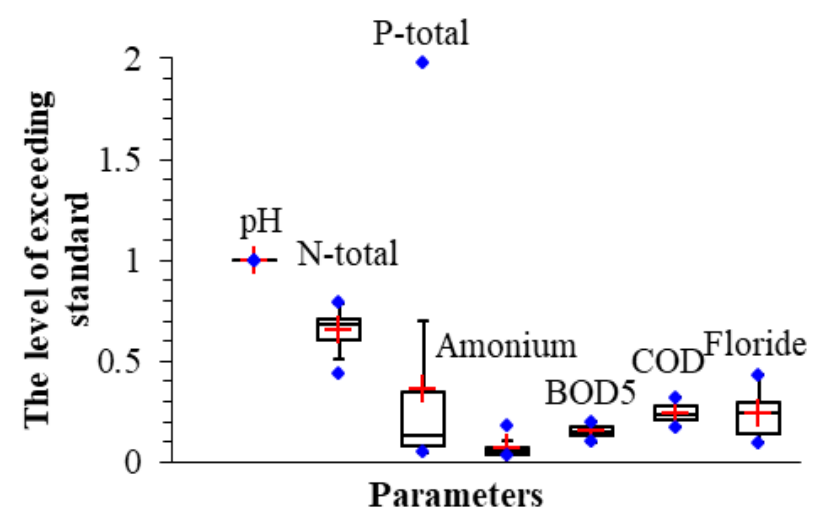

Figure 4: Number of times exceeding a standard of observed parameters in Bien Hoa 2 Industrial Park

As can be seen from Table 4 and Figure 4, most of the pollution parameters are within the permissible limits of column A1 QCVN 40: 2011/BTNMT. However, the maximum P-total concentration exceeded the standard by 1,975 times. Thereby, we see that the current status of wastewater treatment in Bien Hoa 2 Industrial Park has handled most of the organic parameters quite well except the P-total parameter, this will cause organic pollution and cause environmental risks. The receiving school in Dong Nai River.

\section{Loteco Industrial Park}

TABLE 5. Descriptive statistics of exceeding concentration in Loteco Industrial Park

\begin{tabular}{|l|l|l|l|l|l|l|l|}
\hline & $\mathbf{p H}$ & $\mathbf{N}$-total & P-total & Ammonium & BOD $_{5}$ & COD & Fluoride \\
\hline Minimum & 1.0000 & 0.3025 & 0.0300 & 0.0280 & 0.1333 & 0.3067 & 0.0400 \\
\hline Maximum & 1.0000 & 0.5900 & 0.1275 & 0.4440 & 0.4000 & 0.5200 & 0.1440 \\
\hline Mean & 1.0000 & 0.4448 & 0.0731 & 0.0855 & 0.2250 & 0.3856 & 0.0947 \\
\hline
\end{tabular}




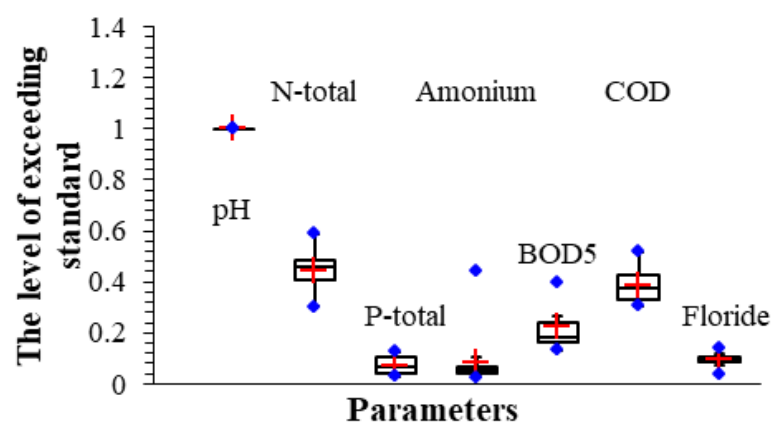

Figure 5. The exceeding level of polluted parameters at Loteco Industrial Park

It can be seen from Table 5 and the Figure 5 presented that the observed parameters at Loteco Industrial Park were within the permitted limits of QCVN 40: 2011 / BTNMT. The parameters that should be considered are parameters of a company by $\mathrm{N}$-total (Maximum number of exceeding standards 0.59 times). Thereby, the current status of wastewater treatment in Amata Industrial Park handled the observed organic parameters well.

\section{Tam Phuoc Industrial Park}

TABLE 6. Descriptive statistics of exceeding concentration in Tam Phuoc Industrial Park

\begin{tabular}{|l|l|l|l|l|l|l|l|}
\hline & $\mathbf{p H}$ & $\mathbf{N}$-total & P-total & Ammonium & BOD $_{5}$ & COD & Fluoride \\
\hline Minimum & 1.0000 & 0.1120 & 0.0035 & 0.0080 & 0.0667 & 0.0800 & 0.0120 \\
\hline Maximum & 1.0000 & $\mathbf{1 . 5 1 0 0}$ & 0.1125 & $\mathbf{3 . 8 8 0 0}$ & 0.4667 & 0.5600 & 0.5040 \\
\hline Mean & 1.0000 & 0.3130 & 0.0261 & 0.4250 & 0.1528 & 0.1878 & 0.1153 \\
\hline
\end{tabular}

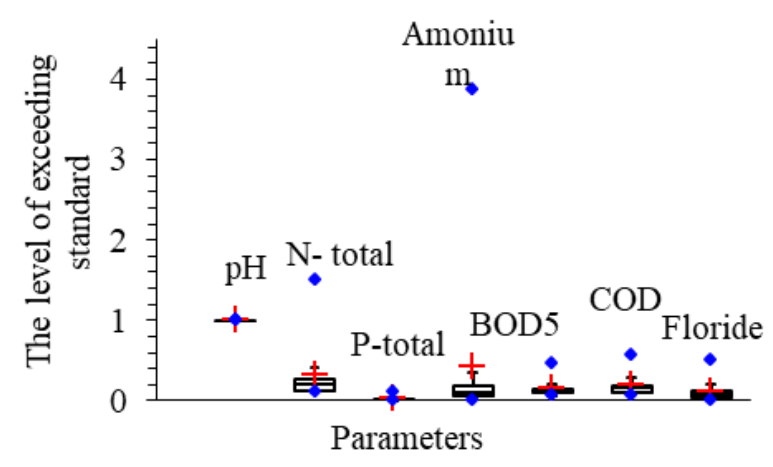

Figure 6. The exceeding level of polluted parameters at Tam Phuoc Industrial Park

It can be seen from Table 6 and Figure 6, it is found that the observed parameters in Tam Phuoc Industrial Park were within the permitted limits of QCVN 40: 2011/BTNMT. However, N-total parameters exceeded the Maximum standard by 1.51 
times, Ammonium exceeded the Maximum standard 3.88 times. Thereby, we showed that wastewater treatment of industrial parks was not good at N-total and Ammonium parameters. This led to organic pollution and caused environmental risks to the environment surrounding the industrial park.

In summary, the most observed parameters of wastewater treatment systems in industrial parks are treated to meet the standards on industrial wastewater in Bien Hoa city. However, some treatment stations didn't stabilize several parameters exceeding the national standard regulation at monitoring of the year like N-total, P-total, Ammonium. Furthermore, the results of the study also provided that the treated wastewater quality of discharged organic pollution into the environment of the industrial parks in Bien Hoa City caused environmental risks to the receiving source.

\subsection{Environmental risk assessment from organic pollution of industrial wastewater in Bien Hoa City}

Wastewater quality of the wastewater treatment plants in industrial parks in Bien Hoa city was polluted including organic parameters such as N-total, P-total, and Ammonium. This caused surface water and environmental risks to human health and the environment. The results of the environmental risk in Bien Hoa City shown as follows.

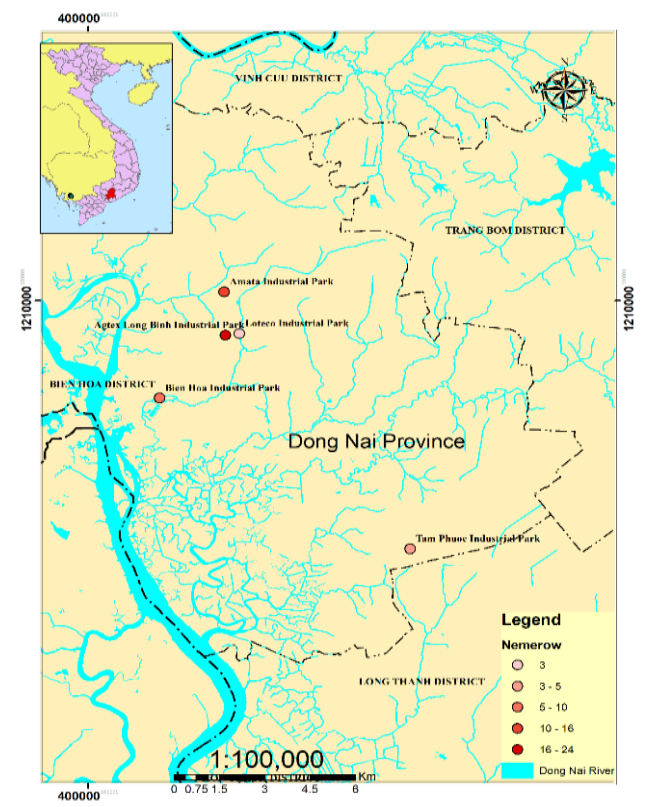

Figure 7. The map of environmental risk

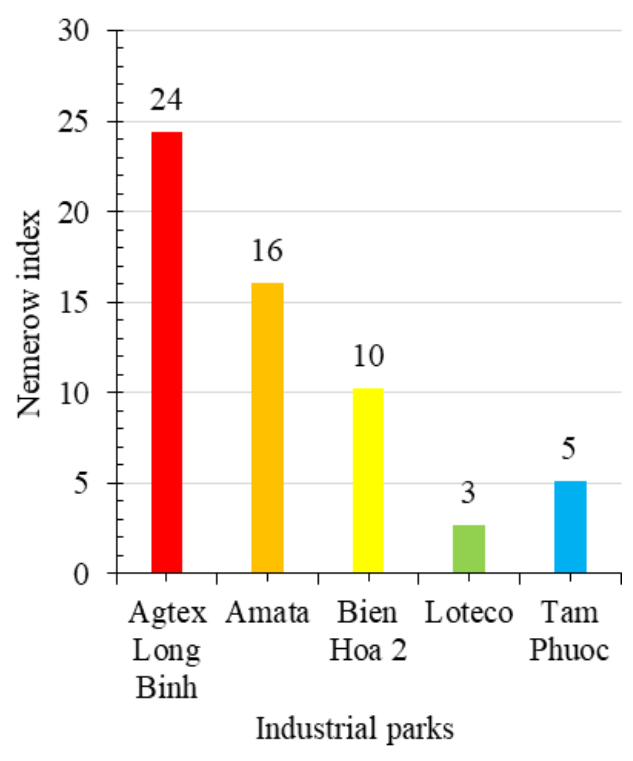

Figure 8 . The risk level of industrial parks

According to Figure 8 and Figure 7, the Nemerow index of industrial parks in Bien Hoa city was high. The risk level for organic pollutants of wastewater in Agtex Long Binh Industrial Park was the highest level $(\mathrm{P}=24)$, followed by Amata Industrial Park $(\mathrm{P}=$ 
16), Bien Hoa Industrial Park $(P=10)$, Tam Phuoc Industrial Park $(P=5)$ and only Loteco Industrial Park was medium level $(\mathrm{P}=3)$. Wastewater of these industrial parks flowing the drainage route to the tributaries of industries, then flowed in Dong Nai river. As a result, this caused the pollution for the water resource of Dong Nai river, impacting on domestic water for millions of people.

Moreover, the results of the study showed that the quality in Bien Hoa City was discharged into receiving resources such Dong Nai River. Organic indicators need to be paid attention to minimize the environmental risks caused by industrial wastewater in the future.

\section{Conclusion}

The process of developing and accelerating the industrialization and modernization of the country as well as the rapid development of Dong Nai province in general and Bien Hoa city in particular has caused pressures on the water environment. The study conducted to assess the environmental risks from organic pollution of industrial parks in Bien Hoa city by using the improved Nemerow index and the geographic information system (GIS). The results of the study showed the current status of wastewater quality in the treatment plants of industrial parks in Bien Hoa city, which still treated thoroughly organic parameters such as N-total, P-total. Ammonium was still exceeding the permitted standard. The results of the study showed that all industrial parks had a high level of environmental risks. This caused adverse impacts on the environment like receiving waste sources of industrial parks in the area, Dong Nai river which received the same amount of wastewater from the industrial park. The results of the environmental risk assessment using the improved Nemerow index are a useful tool to identify the environmental risks from wastewater, helping to quantitatively determine the risk level which to better support making decisions.

Acknowledgment: The authors would like to thank Dong Nai Department of Environment and Natural Resources for supporting the monitoring data.

\section{References}

Covello, V. T., \& Merkhoher, M. W. (1993). Risk assessment methods: approaches for assessing health and environmental risks: Springer Science \& Business Media.

Inengite, A., Abasi, C., \& Walter, C. (2015). Application of pollution indices for the assessment of heavy metal pollution in flood-impacted soil. International Research Journal of Pure and Applied Chemistry, 175-189. 
Islam, M. S., Ahmed, M. K., Raknuzzaman, M., Habibullah-Al-Mamun, M., \& Islam, M. K. (2015). Heavy metal pollution in surface water and sediment: a preliminary assessment of an urban river in a developing country. Ecological indicators, 48, 282-291.

Jie, C., Qing, L., \& Hui, Q. (2012). Application of improved Nemerow index method based on entropy weight for groundwater quality evaluation. International Journal of Environmental Sciences, 2(3), 1284-1290.

Jing, D. (2006). An application of the Nemerow Pollution Index in the quality assessment of the seawater environment in the vicinity of terrestrial drains. Journal of Fujian Fisheries, 1(000).

Nemerow, N. L. (1974). Scientific stream pollution analysis.

Ngo, T. L. T. (2014). Assessment of ecological risks for industrial wastewater in Dung Quat economic zones and industrial parks in Quang Ngai province. University of Education, University of Da Nang.

Pham, T. P. (2013). Assessment and mapping of ecological risks for industrial wastewater in Hoa Khanh Industrial Park and Lien Chieu Industrial Park, Da Nang City. University of Education, University of Da Nang.

Shinta, F. R., Karnaningroem, N., \& Mardyanto, M. A. (2019). Risk Management of Wastewater Treatment in the Wastewater Treatment Plant of PT. X. IPTEK Journal of Proceedings Series(5), 140-149.

Sulthonuddin, I., Hartono, D. M., Utomo, S. W., \& Said, C. A. A. (2019). Water Quality Assessment of Cimanuk River in West Java Using STORET Method. Paper presented at the IOP Conference Series: Earth and Environmental Science.

Tao, T., Yujia, Z., \& HUANG, K. (2011). Water quality analysis and Recommendations through comprehensive pollution index method. Management Science and Engineering, 5(2), 95-100.

Wang, Q., \& Yang, Z. (2016). Industrial water pollution, water environment treatment, and health risks in China. Environmental Pollution, 218, 358-365.

Yi, Y.-J., Sun, J., Tang, C.-H., \& Zhang, S.-H. (2016). Ecological risk assessment of heavy metals in sediment in the upper reach of the Yangtze River. Environmental Science and Pollution Research, 23(11), 11002-11013.

Yulin, H., \& Zhenchang, G. (1989). Water quality evaluation for rivers of Xinjiang in China. IAHS-AISH publication(182), 133-140.

Zhang, Q., Feng, M., \& Hao, X. (2018). Application of Nemerow index method and integrated water quality index method in water quality assessment of Zhangze Reservoir. Paper presented at the IOP Conf. Ser. Earth Environ. Sci. 